\title{
Ergologia: uma abordagem possível para os estudos organizacionais sobre trabalho
}

\author{
Ergology: a possible approach to organizational studies of work
}

\author{
Edvalter Becker Holz ${ }^{1}$ \\ Mônica de Fátima Bianco ${ }^{2}$
}

\section{Resumo}

Busca-se apontar e demarcar como profícuo o uso da Ergologia - abordagem desenvolvida pelo filósofo francês Yves Schwartz - por pesquisadores da área de estudos organizacionais sobre trabalho. Neste artigo teórico a revisão de literatura é utilizada para atingir tal objetivo, abordando os seguintes pontos a respeito da Ergologia: sua gênese e suas concepções sobre o trabalhador e o trabalho; suas principais ferramentas conceituais, a saber, normas antecedentes, valores, renormalização, entidades coletivas relativamente pertinentes, saberes investidos; sua estrutura epistemológica, abrangendo o trabalho como um ambiente de vida, de aprendizagem e de confronto entre saberes, os seus pressupostos e proposições generalizáveis e o dispositivo por meio do qual se dá o seu exercício; uma breve comparação com as perspectivas clínicas do trabalho; a delimitação de sua proficuidade para os estudos organizacionais, abrangendo considerações de pesquisas já realizadas, bem como uma agenda para pesquisas futuras, em que se aponta a possibilidade de um novo olhar sobre discussões consolidadas nessa área, como comportamento e cultura organizacionais, competências e qualidade de vida no trabalho (QVT), e ainda indicações de possíveis consequências para práticas administrativas. Como conclusão, aponta-se a relevância da reflexividade no desenvolvimento de tecnologias gerenciais e da consideração da potencialidade do trabalho real em detrimento das prescrições e dos modelos generalizáveis, bem como se enfatiza o diálogo com os trabalhadores.

Palavras-chave: Estudos Organizacionais. Trabalho. Ergologia. Atividade humana.

\section{Abstract}

This paper aims to point out and mark as fruitful the use of Ergology - approach developed by the French philosopher Yves Schwartz - by researchers of the organizational studies of the work field. This theoretical paper uses literature review to achieve this goal by addressing the following topics about Ergology: its genesis and conceptions about the worker and labor; its main conceptual tools, as previous standards, values, re-normalization, collective entities relatively

Artigo submetido em 15 de junho de 2013 e aceito para publicação em 25 de abril de 2014.

\section{DOI: http://dx.doi.org/10.1590/1679-39519106}

O artigo é resultado parcial de pesquisas realizadas pelos autores com financiamento da Fundação de Amparo à Pesquisa do Espírito Santo - FAPES.

1 Mestre em Administração pela Universidade Federal do Espírito Santo/UFES. Endereço: UFES - Universidade Federal do Espírito Santo, Centro de Ciências Jurídicas e Econômicas, Departamento de Administração, Avenida Fernando Ferrari s/n, Campus Universitário Goiabeiras, Goiabeiras, CEP 29060-900, Vitoria - ES, Brasil. E-mail: e.becker.holz@gmail.com

2 Doutora em Engenharia de Produção pela Universidade de São Paulo/USP; Professora Associada da Universidade Federal do Espírito Santo/UFES. Endereço: UFES - Universidade Federal do Espírito Santo, Centro de Ciências Jurídicas e Econômicas, Departamento de Administração, Avenida Fernando Ferrari s/n, Campus Universitário Goiabeiras, Goiabeiras, CEP 29060-900, Vitoria - ES, Brasil. E-mail: mofbianco@gmail.com 
pertinent, invested knowledge; and its epistemological structure, considering work as an environment of life, learning and knowledge confrontation, its generalizable assumptions and propositions, and the apparatus whereby its exercise works. There is also a brief comparison of work's clinical perspectives, the delimitation of its usefulness for organizational studies, covering considerations of previous researches, as well as an agenda for future ones, where there is the possibility of a new look over consolidated discussions in this area, such as organizational behavior and culture, competences, quality of working life (QWL), and indications of possible consequences for administrative practices. To conclude, it is highlighted the relevance of reflexivity in the development of management technologies and the real work potentiality, in spite of the requirements and generalizable models, as well it is emphasized the dialogue with workers.

Keywords: Organizational studies. Work Ergology. Human activity.

\section{Introdução}

Para Burrel e Morgan (1979), os estudos administrativos tendem a ser funcionalistas principalmente devido ao intervencionismo e pragmatismo comuns em muitas correntes dessa área. A gestão do trabalho humano está historicamente ligada à busca de instrumentos de controle, sendo abundante a literatura que se apresenta como capaz de instrumentalizar o gerenciamento dos "recursos humanos" e promover a adaptação do homem às demandas de desempenho e eficiência (BENDASSOLLI e SOBOLL, 2011). Entretanto, se, por um lado, a Teoria Organizacional constituiu-se tendo por inspiração predominante o modernismo sistêmico (HASSARD, 1993) e, portanto, a premissa de uma diferenciação funcional dos fenômenos sociais (CLEGG, 1990), por outro lado, atualmente e cada vez mais, pesquisadores dessa área têm buscado problematizar e romper com essa tradição.

Assim, no que concerne ao trabalho humano como objeto dos Estudos Organizacionais, tem-se buscado ainda mais o diálogo com outras correntes, de autores diversos (AKTOUF, 2004; CHANLAT, 1994; CLOT, 2007, 2008a; DEJOURS, 1987, 1995; DEJOURS et al., 1993; ENRIQUEZ, 1992; GORZ, 2005; PAGÈS et al., 1980), que procuram romper com a ordem organizacional estabelecida pelo enfoque clássico da Administração. Nessa tendência, o presente artigo se propõe a apontar e demarcar como profícuo o uso da Ergologia - abordagem desenvolvida pelo filósofo francês Yves Schwartz - por pesquisadores da área de estudos organizacionais sobre trabalho. Trata-se de um artigo teórico que se utiliza de revisão bibliográfica para atingir tal objetivo. As principais referências, tanto francesas (DURAFFOURG, DUC e DURRIVE, 2010; DURRIVE, 2011; DURRIVE e SCHWARTZ, 2008; SCHWARTZ, 1998; 2000a; 2000b; 2001; 2002; 2004; 2010a; 2010b; 2010c; 2010d; 2010e; 2011; SCHWARTZ, DUC e DURRIVE, 2010a; 2010b; 2010c; 2010d; 2010e), como brasileiras (ATHAYDE e BRITO, 2011; BRITO, 2004; HENNINGTON, CUNHA e FISCHER, 2011; LIMA e BIANCO, 2009; TELLES e ALVAREZ, 2004; VIEIRA-JÚNIOR e SANTOS, 2012), são aqui articuladas para evidenciar as possibilidades de diálogo com os estudos organizacionais.

Para tanto, o artigo está organizado da seguinte maneira: após esta introdução, discorre-se sobre o surgimento da Ergologia na França e se apresenta sua concepção a respeito do trabalhador e do trabalho; em seguida, suas ferramentas conceituais são resgatadas. Na sessão seguinte, são abordados os aspectos centrais da sua estrutura epistemológica, a saber, o trabalho como ambiente de vida, de aprendizagem e de confronto entre saberes, seus pressupostos e proposições generalizáveis e que servem de guia para análises de situações de trabalho, e ainda o dispositivo por meio do qual se dá seu exercício. A seguir, tem-se uma breve panorâmica das vertentes clínicas do trabalho - Psicodinâmica, Clínica da Atividade e Psicossociologia -, com destaque para os pontos centrais de cada uma, bem como seus pontos de convergência, incluindo aí a Ergologia. Contextualiza-se, então, o uso dessa abordagem no âmbito dos estudos organizacionais, com considerações baseadas em pesquisas já realizadas neste campo, indicando possibilidades de pesquisas futuras e apontando ainda possíveis consequências para práticas administrativas. Nas considerações finais, enfatizam-se o caráter propedêutico deste artigo e a necessidade de novas discussões que tratem da importância da reflexividade na gestão e do diálogo com trabalhadores. 


\section{Ergologia: Gênese e Concepções Importantes para o seu Entendimento}

A Ergologia - assim denominada a partir dos anos 1990 e apresentada como "[...] um projeto de melhor conhecer e, sobretudo, de melhor intervir sobre as situações de trabalho para transformá-las" (SCHWARTZ, 2010d, p. 37) - tem suas origens atreladas a estudos pluridisciplinares a respeito de situações de trabalho em fins de 1970 e início de 1980 na França, e é fruto de experimentações e debates entre profissionais do conceito e protagonistas da atividade de trabalho (ATHAYDE e BRITO, 2011; HENNINGTON, CUNHA e FISCHER, 2011).

Durrive e Jacques (2010, p. 295) explicam que o prefixo "ergo" origina-se de uma palavra grega que significa "ação, trabalho, obra", apontando para a energia e vitalidade do trabalhador. Na Ergologia, portanto, a análise é feita tanto quanto possível "do ponto de vista daquele que trabalha" e se constitui no intuito de investigar o permanente debate de normas e de valores que renovam indefinidamente a atividade humana, concentrando-se sobre a relação que a pessoa estabelece com o meio no qual está engajada (SCHWARTZ, DUC e DURRIVE, 2010d), tendo como intuito "[...] abrir ao máximo o ângulo sobre todas as dimensões da atividade (matriz do viver), ao mesmo tempo analisando-a à lupa" (ATHAYDE e BRITO, 2011, p. 258).

Em seu surgimento, suas principais fontes inspiradoras, conforme relatam Athayde e Brito (2011), foram: uma linhagem no campo da filosofia da vida, que busca compreender a relação entre o homem e o meio; a etnologia da Pré-História, que resgata as historicidades do trabalho; e a Ergonomia da Atividade, importante por ter evidenciado a defasagem entre o trabalho prescrito e o trabalho real. A abordagem ergológica, sem objetivar modelos de análise única, concebe o trabalho como um misto de aspectos técnicos com ação humana, numa relação repleta de singularidades frente às demandas do mundo laboral, propondo então debater outro ponto de vista no mundo organizacional: o ponto de vista do trabalhador, particularmente ausente nas empresas (DURAFFOURG, DUC e DURRIVE, 2010). Para tanto, desenvolve-se como uma proposição analítica do trabalho humano a ser utilizada pelas diversas áreas de saber num movimento pluridisciplinar.

Sendo que seu foco de análise privilegia o ponto de vista do trabalhador, sua concepção a respeito deste passa a ser central e é elaborada tendo por base o conceito de "corpo-si", a seguir esclarecido.

\section{O trabalhador: corpo-si}

Para discorrer sobre o trabalhador e as questões por ele engendradas, a Ergologia não utiliza os conceitos de sujeito ou subjetividade, mas sim de "[...] 'corpo-si', árbitro no mais íntimo da atividade, [...] que não é um 'sujeito' delimitado, definido, mas uma entidade enigmática que resiste às tentativas de ser objetivado" (SCHWARTZ, DUC e DURRIVE, 2010e, p. 196).

Conforme esses autores, o trabalhador é constantemente confrontado com variabilidades na realização de suas atividades, sendo-lhe impossível escapar de microescolhas rotineiras. Diante disso, o corpo-si é o árbitro e gestor dessas variabilidades que o impulsionam a escolher entre trabalhar "por si" ou "pelos outros", gerindo, assim, seu trabalho. Conforme Schwartz, Duc e Durrive (2010e), essa gestão é atravessada por economias do corpo, por sinalizações sensoriais e visuais, por um tipo de inteligência que passa pelo muscular, pelo neurofisiológico, mas que em seguida passa pela inconsciência do próprio corpo e pelo histórico. Em decorrência, a entidade que arbitra e decide não é inteiramente biológica, nem inteiramente consciente ou cultural, e é por isso que a ideia de corpo-si é posta pelos autores como preferível às noções de sujeito ou de subjetividade. Assim tem-se a vantagem de não veicular "[...] certo número de possíveis malentendidos ou de evidências que criam obstáculos", uma vez que todo conceito carrega consigo uma história, apostas e valores (SCHWARTZ, DUC e DURRIVE, 2010e, p. 197). 
Para esses autores, a noção de subjetividade coloca o indivíduo diante de um espelho em que ele se reconhece, um espelho que o transforma em objeto circunscrito numa moldura, descortinando os segredos de sua vida e de sua ação. A noção de corpo-si, ao contrário, remete às profundezas do que se é, um "alguma coisa" que ninguém poderá expressar totalmente em palavras, uma obscuridade que afasta o indivíduo de toda objetivação e que não faz dele "um objeto a ser descrito", restituindo assim a forma pela qual ele sempre escapa, a seu jeito, de ser objetivado. "Ninguém jamais poderá encerrá-lo em uma moldura, por mais sedutora que ela seja” (SCHWARTZ, DUC e DURRIVE, 2010e, p. 198).

Assim, uma vez que busca abarcar o maior número possível de disciplinas para compreender o trabalho humano numa abordagem pluridisciplinar, a Ergologia desenvolve o conceito de corpo-si de modo que não se lhe imponham barreiras epistemológicas drásticas. De modo semelhante, também o conceito de trabalho na referida abordagem diz respeito à sua dimensão de uso, como melhor se explanará a seguir.

\section{O trabalho: usos de si}

Com base no conceito de "corpo-si", Schwartz (2000b) justifica a utilização da palavra "uso" para elaborar sua concepção de trabalho e seu lugar privilegiado na abordagem ergológica: o "uso de si" é a manifestação do "si", sendo este

[...] um sábio desconhecido, o desejo de saúde, o desejo de abrir no mundo cotidiano espaços onde ser norma instituinte, por pouco que se o deseje, que pode tornar possíveis as transferências de afetos e de símbolos entre heranças do desafio infantil e coerções, heranças e possíveis ofertas pelas atividades humanas em cada momento determinado da história; e de tal sorte que esta segunda ordem da realidade não seja simples repetição, mas um retrabalho com profundidade do primeiro (SCHWARTZ, 2000b, p. 47).

Assim, quando se diz que trabalho é uso de si, isso quer dizer que não há execução, mas uso, pois é o indivíduo no seu ser que é convocado; são, mesmo no inaparente, recursos e capacidades infinitamente mais vastos que os que são explicitados e que a tarefa cotidiana requer (SCHWARTZ, 2000a).

Conforme Schwartz, Duc e Durrive (2010d, p. 35), “[...] a ideia de atividade é sempre um 'fazer de outra forma', um 'trabalhar de outra forma"'. Em outros termos, o trabalhador sempre reorganiza o trabalho que lhe é imposto, fazendo escolhas e executando-o de outra maneira, e essa reorganização está ligada à forma como ele sente e enxerga o mundo. Isso porque os indivíduos são únicos e singulares e suas histórias e experiências refletem e interferem na realização do seu trabalho, o que leva todo ato de labor a ser um uso de si por si e pelos outros nos coletivos, repletos de encontros de valores.

Às situações em que o indivíduo precisa fazer escolhas, arbitrando entre valores diferentes ou contraditórios, Schwartz (1998) chama de dramáticas de uso de si. "Dramática" remete ao fato de que no trabalho há sempre um destino a se viver, destino que será determinado pelas escolhas feitas constantemente. Com as escolhas, sabe-se que há os riscos: "[...] de falhar, de criar dificuldades novas, de desagradar" e, ao mesmo tempo, "escolher essa ou aquela hipótese é uma maneira de se escolher a si mesmo - e em seguida de ter que assumir as consequências de suas escolhas" (SCHWARTZ, DUC e DURRIVE, 2010e, p.191).

Uma dramatique é, portanto, o lugar de uma verdadeira micro-história, essencialmente inaparente na qual cada um se vê na obrigação de se escolher ou escolher orientar sua atividade de tal ou tal modo. Afirmar que a atividade de trabalho não é senão uma dramatique do uso de si significa ir de encontro à ideia de que o trabalho é, para a maioria dos trabalhadores, uma atividade simples de "execução", que não envolve realmente sua pessoa (SCHWARTZ, 1998, p. 104). 
Os "usos de si" ocorrem de duas formas: o uso de si por si e o uso de si pelos outros, conforme mencionado anteriormente. $\mathrm{O}$ uso de si por si refere-se ao posicionamento que cada trabalhador toma diante das normas com as quais se depara, confrontando-as e alterando-as, fazendo escolhas, arriscando-se, fazendo uso dos seus gostos, da sua inteligência, da sua história e da sua sensibilidade, recombinando valores e critérios na busca por uma adequação à sua "realidade", o que leva cada ato de trabalho a ser único de trabalhador para trabalhador (DURAFFOURG, DUC e DURRIVE, 2010; SCHWARTZ, 2004; SCHWARTZ, DUC e DURRIVE, 2010d).

Os mesmos autores explicam que o uso de si pelos outros remete a um conjunto de estatutos diversos, uma vez que jamais se trabalha totalmente sozinho. Os "outros" podem ser os colegas de trabalho ou ainda podem estar fora da proximidade imediata; podem ser os avaliadores do trabalho; ou os que pagam pelo trabalho; ou ainda os que fazem a prescrição e as normas científicas, técnicas, organizacionais, gestionárias ou hierárquicas. Tudo isso está presente na intimidade das escolhas que o trabalhador faz sobre esse ou aquele procedimento, fazendo do trabalho uma realidade profundamente coletiva e profundamente individual, visto que é profundamente singular.

Além dessas noções centrais, ainda outras ferramentas conceituais figuram no aporte teórico ergológico, visando ampliar a compreensão sobre o trabalho humano e auxiliar os pesquisadores em suas análises, conforme se resgata na sessão seguinte.

\section{Ferramentas Conceituais}

Antes de abordá-las, é indispensável considerar que os conceitos da Ergologia consistem em definições contextualizadas e, portanto, não seguem a lógica de um dicionário com referências que se pretendem definitivas (DURRIVE e SCHWARTZ, 2008). Conforme esclarecem esses autores, os conceitos desenvolvidos pela Ergologia obedecem a uma ordem aparentemente contraditória, porém necessária: por um lado, obedecem a uma disciplina ou exigência epistêmica, ou seja, são construídos de modo a serem libertados da aderência local, numa tentativa de neutralizar, na medida do possível, a dimensão histórica dos fenômenos sociais; por outro lado, são também, eles mesmos, ergológicos, ou seja, são aproximados o máximo possível das configurações de saberes e de valores gerados pela atividade.

Esse quiasmo na elaboração conceitual ergológica, conforme explica Schwartz (2002, p. 126), faz-se necessário tendo em vista que "[...] toda atividade humana, localmente reprodutora de história, vive e encontra suas ferramentas num universo de conceitos que só se tornam eficientes ao neutralizar a história. De modo inverso, a implementação dessa disciplina epistêmica se opera no tecido histórico da cultura humana. Portanto, ela é, enquanto implementação, um processo ergológico". Desse modo, na Ergologia, "[...] o conceito é um instrumento para pensar; ele permite recortar, definir, generalizar, abstrair-se do presente", porém, "forma com a vida uma unidade dialética" (DURRIVE e SCHWARTZ, 2008, p. 24).

Postas essas considerações e já tendo sido anteriormente explanadas as noções de corpo-si e de usos de si, centrais na Ergologia, outras, cuja compreensão permite seu melhor entendimento, ainda precisam ser resgatadas.

Uma delas diz respeito à preocupação com eficácia e racionalidade comumente presente nas organizações e expressa no que os ergonomistas chamam de "trabalho prescrito", ou seja, "o trabalho que foi determinado, 'cientificamente pensado' por pessoas que fizeram cálculos de tempo, de eficácia, portanto que estudaram tudo, de fato, detalhadamente" (SCHWARTZ, 2010d, p. 40). Visando à menor perda de tempo, bem como encontrar a maneira ótima para realização, o trabalho prescrito é definido de modo externo e imposto aos trabalhadores.

No entanto, conforme Duraffourg, Duc e Durrive (2010, p. 70), o prescrito tende a se dissolver, ou seja, pode estar "[...] formalizado nos livros sobre a organização, ele pode ser afixado num mural, ser objeto de 
esquemas, modelos, razões. Ele é registrável, é visível, pode ser verbalizado. Por outro lado, tudo o que é da ordem do real é dificilmente visto e expresso. Quantos trabalhadores dizem: 'eu estou acostumado', e não conseguem verbalizar sua maneira de fazer!". Em razão disso, a Ergologia privilegia o conceito de "normas antecedentes", que engloba o conceito ergonômico de trabalho prescrito (TELLES e ALVAREZ, 2004).

Conforme Vieira-Júnior e Santos (2012, p. 94), o conceito de "normas antecedentes"

[...] é mais abrangente que o seu precursor [trabalho prescrito], por incorporar várias dimensões presentes nas situações de trabalho, como: a) as aquisições de inteligência do trabalhador; b) as experiências coletivas; c) o saber-fazer; d) as construções históricas analisadas como patrimônio cultural e científico; e) a dimensão dos valores, que transcende a questão monetária e se posiciona na esfera do político, dos debates e dos conflitos que findam por compor o caráter híbrido desse conceito.

As normas antecedentes referem-se, portanto, ao modo como experiências coletivas produzem normas situadas num tempo-espaço laboral, considerando-se ainda a parcela de singularidade de cada trabalhador que compõe o grupo, uma vez que estão subjacentes nelas valores coletivos e individuais (SCHWARTZ, DUC e DURRIVE, 2010d).

O que leva a outro conceito relevante, o de "valores", que, na Ergologia, refere-se ao

[...] peso que se atribui mais ou menos às coisas; uma hierarquia, uma categorização própria a cada um a propósito do que se estima, prefere, ou pelo contrário se negligencia, rejeita. Em certa medida, é a tentativa de cada um de ter uma mestria sobre o meio no qual se encontra (exemplo: um escritório personalizado). O indivíduo não inventa sozinho nem completamente os seus valores, mas retrabalha incessantemente os que o meio lhe propõe (DURRIVE e SCHWARTZ, 2008, p. 27).

Os valores atravessam o micro da atividade, assim como atravessam toda a sociedade e explicam por que uma pessoa faz as coisas de certa forma e não de outra, por que ela tem tal tipo de relação com as pessoas e não outro (DURAFFOURG, DUC e DURRIVE, 2010).

Schwartz (2010d) enfatiza ainda que sempre há valores em jogo na atividade, uma vez que as pessoas fazem escolhas - conscientes ou inconscientes. E, se fazem escolhas, é em razão de critérios e, portanto, em razão de valores, e são os valores que levam à reconfiguração das normas, ou seja, às "renormalizações", outro conceito capital.

Renormalizações são: “[...] as múltiplas gestões de variabilidades, de furos das normas, de tessitura de redes humanas, de canais de transmissão que toda situação de trabalho requeira, sem, no entanto, jamais antecipar o que elas serão, na medida em que essas renormalizações são portadas por seres e grupos humanos sempre singulares, em situações de trabalho, elas mesmas também sempre singulares” (SCHWARTZ, 2011, p. 34).

As renormalizações, conforme o autor, decorrem de um desencontro entre os valores que permeiam as normas antecedentes e os valores dos trabalhadores. Ocorrem, então, "debates de normas" em todas as atividades, inclusive nas mais ínfimas. Em qualquer que seja a situação, há sempre uma negociação da atividade com as normas anteriores a ela (SCHWARTZ, DUC e DURRIVE, 2010d). Isso porque, de acordo com esses autores, cada ser humano tenta recompor, em parte, o meio de trabalho de acordo com o que ele próprio é e com o que ele deseja que seja o universo que o circunda, levando a um tipo de recriação permanente e, como consequência, a uma defasagem entre o trabalho prescrito e o trabalho como realmente é feito. Nesse processo, questões e debates de escala macro aparecem no mais simples ato de trabalho, bem como o mais simples dos atos de trabalho pesará nas mudanças de maior amplitude (SCHWARTZ, DUC e DURRIVE, 2010d). 
Cabe ressaltar ainda as noções de "entidades coletivas relativamente pertinentes" e de "saberes investidos". A primeira é utilizada para diferenciar as entidades coletivas daquelas definidas por organogramas ou por lugares, postos e responsabilidades, remetendo, em vez disso, aos coletivos dentro de um "campo ergológico", ou seja, que diz respeito à atividade humana, uma vez que suas fronteiras não são predefinidas, mas sim assentadas pela atividade num dado momento, como "sinfonias sem maestro" (SCHWARTZ, 2010a).

A noção de "saberes investidos", por sua vez, refere-se aos saberes que ocorrem em aderência, em capilaridade com a gestão de todas as situações de trabalho, e que são adquiridos nas trajetórias individuais, coletivas e singulares (SCHWARTZ, 2010b). Ou seja, são os saberes diversos constituídos e retrabalhados coletiva e individualmente nas atividades.

A relação entre todos esses conceitos pode ser mais bem compreendida pela observação da estrutura epistemológica da Ergologia, que será abordada a seguir pelo enfoque em três pontos principais.

\section{Estrutura Epistemológica}

Delimitar a estrutura epistemológica da Ergologia é um risco, uma vez que se trata de uma abordagem recente e em construção e, principalmente, porque esta não se pretende uma disciplina específica de um campo de saber, mas uma abordagem pluridisciplinar, uma disciplina do pensamento que convoca todas as áreas do saber, conforme já exposto. Assim, a seguir são destacados alguns dos principais pilares sobre os quais se desenvolve essa forma de produção de conhecimento, quais sejam: o trabalho como ambiente de vida, de aprendizagem e de confronto entre saberes; seus pressupostos e proposições generalizáveis; seu exercício, um dispositivo dinâmico de três polos.

\section{Ambiente de vida, de aprendizagem e de confronto entre saberes}

A noção de trabalho como uso de si leva a conceber que o "[...] trabalho não é só uma realização técnica e/ou mecânica, a qual muitos o reduzem" e a admitir que "[...] o trabalho e o Homem estão íntima e enigmaticamente ligados" (TRINQUET, 2010, p. 96), o que dissipa a distinção ergonômica entre atividade de trabalho e atividade humana (GUÉRIN, LAVILLE, DANIELLOU et al., 2001), uma vez que entre uma ação humana qualquer e um trabalho economicamente caracterizado não há descontinuidade absoluta: ambos são comensuráveis, haja vista que envolvem uma experiência, uma negociação problemática entre normas antecedentes e as normas de indivíduos singulares, sempre a serem redefinidas "aqui e agora" (SCHWARTZ, 2004; 2010c). Para falar dessa relação, Schwartz recorre a Canguilhem (1947; 1992; 1994; 1999) e percebe na singularidade do trabalho um desejo de saúde. Isso porque

[...] a concepção de homem no mundo é o ponto de partida da reflexão do filósofo Yves Schwartz, [...] ele raciocina a partir do "meio de vida", que, no caso presente, designa não o ambiente natural ou as condições sociais que se possam analisar independente dos pontos de vista individuais, mas o mundo tal como cada um tende a reconstruir em torno de si, a fim de viver como ser singular (DURRIVE, 2011, p. 48).

Com base na concepção de que "[...] o que caracteriza o homem é, na verdade, a capacidade de se mover dentro de um universo de normas" (DURRIVE, 2011, p. 49), e considerando que todo homem quer ser sujeito de suas normas (CANGUILHEM, 1947), pode-se afirmar que "viver é irradiar". Ou seja, viver é organizar o meio de acordo consigo mesmo como centro de avaliação, de valorização, de decisão concernente ao seu próprio agir (DURRIVE, 2011), uma vez que saúde, conforme Canguilhem (1999; 1992), não diz respeito a se enquadrar no que se coloca como o normal, mas sim se refere a ser normativo, isto é, à capacidade e necessidade de instituir normas e poder viver baseado nelas. 
Assim, quando se menciona que o trabalho é um uso de si, envolvendo a singularidade do trabalhador, suas escolhas e arbitragens, seu enfrentamento em relação às normas impostas e ainda o retrabalho dessas normas de acordo com valores de vida do trabalhador, percebe-se que é tudo isso em jogo no ato mesmo de viver e de tentar viver com saúde, ou seja, de tentar viver de acordo consigo mesmo num ambiente em parte imposto, em parte coercitivo, mas em parte modificável, e esse processo será sempre debatido e renormalizado por usos de si no âmbito das entidades coletivas de trabalho.

Outro ponto a se observar como pano de fundo dos conceitos da abordagem ergológica é a relação entre trabalho e aprendizagem. O trabalho é uma atividade intelectual, uma vez que, para executá-lo, é necessário antes pensar. Mas, do mesmo modo que é preciso aprender a fazer, também se aprende fazendo. Assim, “[...] é preciso operar uma análise interna da atividade para perceber particularmente aquilo que ela comporta de conceitualização" (PASTRÉ, 2006, p. 109).

De um lado, toda atividade é aplicação de um protocolo e, de outro, um encontro de encontros a gerir. Desse modo, por mais prescritiva que possa ser uma tarefa, o que vai orientá-la e guiá-la na sua execução é também o conhecimento a respeito da situação de trabalho do operador. Em outras palavras, "[...] é a partir da situação na qual se encontra o operador que ele vai organizar sua ação e mobilizar eficazmente certo número de conhecimentos" (DURRIVE, 2011, p. 59), ou seja, ele vai gerir seu fazer baseando-se também em suas próprias normas, muitas delas manifestas somente no momento da ação. No conceito de renormalização engloba-se a historicidade dos trabalhadores, o que lhes provê meios de reconfigurar as normas antecedentes, isto é, as normas instituídas no coletivo do trabalho (BIANCO, ALMEIDA e BINDA, 2012).

É preciso considerar ainda que é impossível para ele pensar integralmente a situação de modo antecipado, do que resulta a dupla necessidade de pensar ao agir; assim, um reforça o outro, fazendo da atividade algo intelectual e algo vital (DURRIVE, 2011). Em outros termos, “[...] não há atividade que não comporte, mesmo que minimamente, uma parte de aprendizagem" (RABARDEL e PASTRÉ, 2009, p. 232). Dessa relação resultam saberes investidos, ou seja, saberes imanentes à atividade.

Articulando esses dois pontos, a Ergologia relaciona ao trabalho um ambiente de vida e um ambiente de aprendizagem. Da articulação de ambos, emerge outro aspecto epistemológico fundamental para se compreender e utilizar a abordagem Ergológica: os saberes portados e formulados pelo pesquisador devem ser lançados para confronto com os portadores da experiência, os portadores da aprendizagem estabelecida na atividade e no ambiente de vida. O trabalhador é, portanto, o elemento central da investigação (ODDONE, 2007), e o pesquisador deve estar disposto a aprender com ele (SCHWARTZ, DUC e DURRIVE, 2010b).

Com base no que se expôs, podem-se evidenciar três pilares na sustentação teórica da Ergologia: o trabalho como ambiente de vida, de aprendizagem e de confronto entre saberes científicos e saberes imanentes à atividade. Nesse sentido, respectivamente, Georges Canguilhem, Pierre Pastré e Ivar Odonne constituem uma tríade inspiradora para a construção da epistemologia da abordagem Ergológica de Yves Schwartz.

Mediante esses aspectos e considerando o aporte teórico resgatado, alguns pressupostos e proposições são dados para guiar as análises, como se expõe a seguir.

\section{Pressupostos e proposições generalizáveis}

A análise ergológica do trabalho humano segue quatro pressupostos, resumidos por Brito (2004): pensar o geral e o específico, segundo a dialética entre o universal e o singular; visar à articulação entre as diversas disciplinas e, sobretudo, à interrogação sobre seus saberes; encontrar em todas as atividades situadas as normas antecedentes e as variabilidades, as normas que se impõem e as normas que se instauram; promover um regime de produção de saberes sobre o humano, pois o encontro sempre histórico entre os dois saberes (científicos e práticos) não pode ser antecipado, é sempre uma descoberta. 
Também quatro proposições universais são formuladas para guiar as análises, esclarecidas por Schwartz (2010d): existe sempre uma distância entre o trabalho prescrito e o realizado; esta distância é sempre ressingularizada; a entidade que conduz e arbitra essa distância é uma entidade simultaneamente "alma" (sem qualquer conotação religiosa) e corpo; a arbitragem mobiliza um complexo de valores: o trabalho é sempre encontro de valores.

Convergindo todos esses pontos, a abordagem ergológica, como um exercício de produção de conhecimento e intervenção, efetua-se com o desenvolvimento de um dispositivo dinâmico de três polos, a seguir explicitado.

\section{Seu exercício: um dispositivo dinâmico de três polos}

$\mathrm{Na}$ abordagem ergológica, “[...] intervir envolve dominar os saberes que se vão compartilhar, mas envolve também reconhecer o saber do outro, seu semelhante, na medida em que ele é também permanentemente portador de diferenças recriadoras em sua atividade; consequentemente, envolve estar igualmente disponível para aprender com ele" (SCHWARTZ, DUC e DURRIVE, 2010b, p. 265). Portanto, o exercício da Ergologia propõe colocar em diálogo os saberes científicos com os saberes imanentes à atividade, por meio de um dispositivo dinâmico de três polos (TRINQUET, 2010), cuja proposta central é o confronto entre os portadores do conhecimento conceitual e os trabalhadores, portadores dos saberes imanentes à atividade (SCHWARTZ, 2000a). Em geral, por meio do dispositivo dinâmico de três polos (DD3P), busca-se fazer com que a aprendizagem formal seja alimentada pela aprendizagem informal, tendo como foco os saberes e os valores que circulam e renovam indefinidamente a atividade de trabalho (SCHWARTZ, DUC e DURRIVE, 2010b; SOUZA e BIANCO, 2007).

Para tanto, o DD3P constitui-se tendo por base o confronto e a acareação entre saberes técnicos e científicos (polo I) com as experiências e os saberes imanentes às atividades (polo II), em que se situam forças de convocação e reconvocação para o retrabalho desses saberes. Tal acareação é realizada sob o olhar de uma exigência filosófica (polo III) capaz de provocar a interfecundação entre os dois primeiros polos e de renovar os saberes formais e disciplinares rumo à transformação dos meios de vida, numa postura ética e reflexiva (BRITO e ARANHA, 2011; BOTECHIA e ATHAYDE, 2007; SCHWARTZ, 2002; SCHWARTZ, DUC e DURRIVE, 2010b; SOUZA e BIANCO, 2007; TRINQUET, 2010).

O exercício ou ofício da Ergologia consiste, portanto, em um constante movimento de confrontação dos saberes científicos acumulados com os saberes em devir na atividade, visando seu retrabalho e sua contextualização por intermédio da validação ou interpelação epistemológica e ética, renovando indefinidamente o saber, uma vez que o triângulo saberes/valores/atividade ao qual são remetidos os conceitos acumulados não cessa de renormalizar.

Esse movimento, denominado "socratismo em duplo sentido" (SCHWARTZ, DUC e DURRIVE, 2010b), visa à produção de saberes acerca da vida social, da atividade e da história para conhecer as normas antecedentes e compreender os recentramentos operados na atividade. A difícil operacionalização desse dispositivo, conforme os autores, coloca como exigência a "humildade intelectual", não havendo uma técnica ou maneira única ou pré-estabelecida para sua realização; cada DD3P tomará forma diversificada, em que o mais importante é o terceiro polo, uma vez que ao mesmo tempo trata de saberes e de valores e da relação com o outro, tomado na qualidade de microrrecriador permanente.

Esclarecidos assim os principais pontos epistemológicos da construção e uso da Ergologia, uma breve comparação sua com outras abordagens de estudo do trabalho denominadas Clínicas pode ainda promover um melhor entendimento a seu respeito, sendo esse o objeto da sessão seguinte. 


\section{A Ergologia e as Clínicas do Trabalho}

Considerando que discussões de natureza comparativa demandam cuidado, clareza e aprofundamento, cabe ressaltar que, na presente sessão, busca-se tão somente traçar uma breve panorâmica comparativa da Ergologia com as perspectivas clínicas do trabalho. Assim, o que aqui se expõe é um breve paralelo, com destaque para alguns dos principais aspectos da Psicodinâmica, da Clínica da Atividade e da Psicossociologia, elencadas por Bendassolli e Sobol (2011) como as perspectivas clínicas do trabalho na contemporaneidade. Esse termo, "clínicas do trabalho", remete ao conjunto de disciplinas que abordam questões relativas à subjetividade nos contextos laborais, ou seja, às tentativas de compreender a relação entre fatores subjetivos e a atividade, encontrando-se entre as diferentes perspectivas alguma polissemia e ambiguidade (LIMA, 2011).

Um dos pioneiros nessa empreitada, Dejours (1980; 1987; 1995; 1996a; 1996b; 2000), fundador e representante maior da Psicodinâmica do Trabalho, esclarece que seu surgimento deu-se pela confrontação entre a Psicanálise, a Psiquiatria e a Ergonomia, tendo no seu centro a discussão em torno de três questões essenciais: o sujeito, a saúde e o trabalho. Conforme esclarece Lima (2011), no percurso de desenvolvimento da Psicodinâmica, seu centro de investigação se desloca da patologia para a normalidade, sendo esta concebida como um compromisso entre o sofrimento e as defesas constituídas individual e coletivamente para controlá-lo.

A Clínica da Atividade, por sua vez, desenvolvida por Clot (2001; 2007; 2008a; 2008b; 2009), concebe a subjetividade em sua relação com a atividade tendo por base as reflexões de Vygotsky, que percebia o homem, a cada momento, como pleno de possibilidades, conforme esclarece Lima (2011). Ao dissertar sobre a perspectiva teórica de Yves Clot, essa autora resume a proposta da Clínica da Atividade como a de criar condições que permitam restaurar o "poder de agir" dos sujeitos nos seus contextos de trabalho, em vez de simplesmente fazer um "inventário de queixas" ou propor um diagnóstico dos problemas, apresentando, em seguida, sugestões de mudanças. Assim, conforme a autora, a Clínica da Atividade coloca-se numa posição bastante diferente e, em certos aspectos, inversa àquela adotada pela Psicodinâmica do Trabalho: a ação na Clínica da Atividade também se volta para o engajamento subjetivo dos operadores, mas apenas em um primeiro nível; em um segundo nível, ela visa à transformação das atividades reais, ensejando proporcionar uma reorganização do trabalho pelo coletivo e incitando o trabalhador a agir sobre sua própria atividade.

Já a Psicossociologia, conforme elucidam Carreteiro e Barros (2011), tem origem com trabalhos de intervenção em associações e se afirma no meio acadêmico por meio de autores como Max Pagès, Eugene Enriquez, Andre Lévy, Guy Palmade, Jean Dubost e Jean Rouchy. Conforme pontuam as autoras, trata-se de uma perspectiva interdisciplinar cujas pesquisas conferem lugar importante à Psicanálise, História, Antropologia, Sociologia e Política. Dessa perspectiva, o trabalho é fundamentalmente espaço de troca com os outros, é o que permite "sair de si", construir e manter engajamentos, possibilitando ao sujeito inscreverse em uma história coletiva, sendo então o aspecto essencial da Psicossociologia a relação entre o individual e o coletivo, o psíquico e o social, o particular e o geral (CARRETEIRO e BARROS, 2011).

Apesar de Bendassolli e Soboll (2011) incluírem a Ergologia no rol das clínicas do trabalho, não se pode atribuir tal caracterização a Yves Schwartz, que a apresenta apenas como uma disciplina do pensamento (SCHWARTZ, 2001), "[...] um projeto de melhor conhecer e, sobretudo, de melhor intervir sobre as situações de trabalho, para transformá-las" (SCHWARTZ, 2010d, p. 37), uma "[...] aprendizagem permanente dos debates de normas e de valores que renovam indefinidamente a atividade: é o 'desconforto intelectual"" (SCHWARTZ, DUC e DURRIVE, 2010d, p. 30), e ainda "[...] uma tentativa de compreender o vai e vem do microscópico do trabalho ao macroscópico da vida social" (SCHWARTZ, DUC e DURRIVE, 2010b, p. 262). Para tanto, o foco da abordagem ergológica recai sobre o trabalho em sua dimensão de atividade humana, rica em alternativas e engajada em escolhas (SCHWARTZ, RUZZA e BRIS, 2010), e o termo "atividade" é empregado para designar "[...] um impulso de vida, de saúde, sem limite predefinido, que sintetiza, cruza e liga tudo o que se representa separadamente (corpo/espírito; individual/coletivo; fazer/valores; privado/profissional; imposto/desejado, etc.)" (DURRIVE; SCHWARTZ, 2008, p. 23). 
Conforme ressalvam Bendassolli e Soboll (2011), as clínicas do trabalho não constituem uma escola de pensamento, tampouco as abordagens mencionadas podem ser ditas homogêneas, quer em termos epistemológicos, teóricos ou metodológicos. Ainda assim, os autores apresentam alguns pontos comuns entre a Psicodinâmica, a Clínica da Atividade, a Psicossociologia e também a Ergologia.

O primeiro deles é o interesse pela "ação" no trabalho como poder de agir dos sujeitos e dos coletivos - o termo "poder" refere-se não a classes sociais, à posse de recursos escassos, à capacidade de influência ou à autoridade, mas àquele encontrado no nível do "ato", como o poder sobre si mesmo (no sentido do poder do "uso de si"), o poder sobre a atividade (a maestria sobre meios-fins), o poder sobre a atividade de outros; o poder sobre as resistências como enfrentamento a restrições e frustrações.

Ainda conforme os autores, as quatro vertentes compartilham também o entendimento sobre o "trabalho" no sentido de que ele não se restringe à sua institucionalização econômica, isto é, o emprego, mas é apreendido enquanto atividade sustentada por um projeto de transformação do real e de construção de significados pessoais e sociais.

Outro pondo de convergência apontado por Bendassolli e Soboll (2011) é a defesa de um "sujeito" que se desenvolve e se afirma no seu confronto com o real, em contraste com o indivíduo que se resume a captar informações do ambiente, processando-as e devolvendo-as na forma de "ações comportamentais", como se nota em abordagens das psicologias cognitivas e experimentais do trabalho.

O quarto ponto de convergência apontado pelos autores é o fato de que as perspectivas mencionadas questionam-se sobre seus propósitos, ou seja, sobre com o que buscam contribuir. No que concerne à Ergologia, trata-se de destacar que seu princípio epistemológico central na produção de saber sobre a atividade humana reside na dialética entre a norma antecedente e a renormalização (NOUROUDINE, 2011), ou seja, de elucidar no mais ínfimo ato de trabalho o debate de valores ligado ao debate de normas concernentes à ação, por meio das dramáticas de usos de si.

O aporte conceitual ergológico, bem como os pressupostos e proposições até aqui abordados, têm sido introduzidos por pesquisadores no âmbito dos estudos organizacionais, e já figuram algumas pesquisas cujos apontamentos e conclusões são resgatados na próxima sessão, na qual também são indicadas novas possibilidades de pesquisas e possíveis consequências para práticas administrativas.

\section{A Ergologia e os Estudos Organizacionais}

Apesar da incipiência do impacto da Ergologia sobre os Estudos Organizacionais envolvendo o trabalho, algumas pesquisas já figuram e não se poderia deixar de fazer menção a seus apontamentos e contribuições, bem como apontar possibilidades de discussões futuras e impactos para práticas administrativas, conforme se segue.

\section{Considerações com base em pesquisas realizadas}

Utilizando os conceitos de uso de si por si e uso de si pelos outros para analisar situações de trabalho no Centro de Operações de uma empresa de distribuição de energia elétrica instalada no Sudeste do Brasil, Souza e Bianco (2007) problematizam o fato de que os estudos organizacionais analisam as relações de trabalho geralmente dividindo-as em dois grandes grupos: um formado pelos funcionários que ocupam posição gerencial e outro composto pelos demais membros da organização que não ocupam nenhum cargo gerencial. O que, conforme os autores, constitui a clássica divisão do trabalho entre gestores e geridos, divisão essa defendida e considerada como algo natural e necessária por diversos teóricos (MINTZBERG, 1992; 1995; PETTIGREW, 1973; PFEFFER, 1981; WATSON, 1982). Souza e Bianco (2007) apontam a necessidade de se considerar o rompimento com a ideia de que em uma organização há claramente "gestores 
e geridos", com papéis antagônicos, sendo os "geridos" não gestores. Isso porque o uso de si por si e por outros ocorre em todos os níveis hierárquicos, fazendo com que todos os membros de uma organização estejam a todo tempo gerindo o seu trabalho e as suas relações sociais, em maior ou menor intensidade.

Nesse mesmo contexto organizacional, Machado et al. (2007), por sua vez, pontuam que o fato de gerir a própria atividade, "transgredindo" regras ou normas, pode ser fator vital, em especial em trabalhos que envolvam risco de morte. Isso porque a complexidade da gestão da atividade mostra que a saúde relacionada ao trabalho não é apenas uma questão individual, mas coletiva, e envolve aspectos como exigência de rapidez e de resultados, flexibilização das relações de trabalho e ainda condições inadequadas para realização das atividades.

Lima e Bianco (2009), por sua vez, revelam nuances do mundo do trabalho pela lente ergológica realizando um estudo em uma empresa atuante no Brasil na área de fabricação de tubos flexíveis para exploração de petróleo, focando os usos de si na gestão das atividades. Os autores ressaltam que a compreensão da singularidade e complexidade da atividade de trabalho permite entender o trabalhador como ser humano: com instintos, emoções, necessidades, escolhas e decisões - estas últimas, muitas vezes, são tomadas com base em experiências passadas, com ação no presente e efeito no futuro. Isso porque, ao realizar seu trabalho, o trabalhador sempre o transforma, renormalizando-o por meio de suas superações e como forma de enfrentamento das suas imposições. Os autores relatam ainda a possibilidade de intervenção na empresa, ou seja, de construir instruções de trabalho que contemplem os objetivos e parâmetros dos processos e não os modos operatórios, mudando o foco do "como fazer" para "o que fazer", além de elementos da ordem do imponderável.

Orientados pela perspectiva ergológica e com o objetivo de colocar em evidência a dinâmica do trabalho efetuado por técnicos em eletrônica em uma empresa prestadora de serviços localizada também no Sudeste do Brasil, Mezadre e Bianco (2012) corroboram que o trabalhador, ao fazer uso de si quando enfrenta as demandas do trabalho, permite que suas capacidades sejam requeridas e aprimoradas constantemente, transitando da situação atual e real do trabalho a possibilidades futuras.

Bianco, Almeida e Binda (2012), por sua vez, utilizam-se do aporte ergológico para fazer uma análise do trabalho de agentes comunitários de saúde que atuam em duas unidades de saúde prestadoras de serviço à população residente em diferentes bairros de uma capital brasileira. Para os autores, a Ergologia traz a noção de trabalho como espaço de transformação, convertendo "o trabalho em algo vivível" (BIANCO, ALMEIDA e BINDA, 2012, p. 365). A transformação do trabalho na organização é uma possibilidade que emerge da relação entre trabalho e trabalhador, "[...] no processo de verbalização do seu saber fazer, criando quando a norma não prescreve e recriando quando a prescrição de fato não prevê e não conhece o real, porque jamais é capaz de antecipá-lo. Nas lacunas emergem os valores, as dramáticas e diferentes formas de dedicação a uma causa" (BIANCO, ALMEIDA e BINDA, 2012, p. 365).

Com base nessas pesquisas, pode-se evidenciar que conceitos como corpo-si, usos de si, normas antecedentes, renormalização, entidades coletivas relativamente pertinentes e saberes investidos figuram como indicativo para se repensar a organização do trabalho da ótica da gerência, tradicionalmente prescritiva da tarefa, e reforçar a necessidade de um deslocamento de foco para o trabalho real, ou para o trabalho como atividade humana, repleta de singularidades. De modo geral, as pesquisas contribuem para a desnaturalização de discursos gerenciais que, apesar de contemporâneos, em muito ainda preservam a lógica tayloristafayolista de planejamento, organização, direção e controle, pressupostos que essencialmente visam anular as singularidades do trabalho real em detrimento da prescrição e da generalização. Além do mais, as pesquisas convergem para um movimento de restituição da atividade de trabalho ao trabalhador, vínculo bruscamente rompido com a instauração e disseminação do modelo taylorista de produção, quando se busca levar ao máximo a separação entre concepção e execução, o monopólio do conhecimento do trabalho pela gerência e o fracionamento e a simplificação do gesto produtivo humano.

Considerando essas discussões, pode-se argumentar que as possibilidades de pesquisa são diversas, dado o enfoque ergológico sobre as dimensões singulares que interferem no trabalho humano e, consequentemente, 
no mundo organizacional. A despeito dessa multiplicidade, podem ainda ser enfatizadas possibilidades de um novo olhar - olhar ergológico - sobre algumas discussões já tradicionais nos estudos organizacionais, conforme se elenca a seguir.

\section{Possibilidades de pesquisas futuras}

Por colocar o debate de valores ligado ao debate de normas como elemento chave das decisões cotidianas dos trabalhadores, a Ergologia figura, por exemplo, como possibilidade de um novo olhar sobre discussões em torno da temática da "cultura organizacional". Conceito plural e não consensual, a cultura organizacional não raramente é vista como fundada por variáveis organizacionais, ou algo que objetiva estabelecer formas homogêneas de conduta (COELHO-JÚNIOR e BORGES-ANDRADE, 2004), o que vai de encontro à relevância ergológica dada às singularidades e aos valores dos trabalhadores como fatores centrais na dinâmica geradora de normas, incessantemente retrabalhadas.

Da noção de trabalho como uso de si também podem emergir investigações que a confrontem com os termos/conceitos "recursos humanos" ou "ativos humanos", que tradicionalmente concebem o trabalhador como passível de instrumentalizações (BENDASSOLLI e SOBOLL, 2011). À luz das noções de corpo-si e uso de si, pode-se problematizar a parcialidade gerencial dessas noções, uma vez que todo ser humano no trabalho quer ser sujeito de suas normas e, portanto, será, em algum nível, gestor de sua atividade, o que é singular e não antecipável.

A concepção de uso de si faz interrogar ainda duas noções: a de "comportamento organizacional", fator posto não raramente como devendo ser gerenciado, e de "modelos mentais", transmitidos na forma de pressupostos, histórias, imagens e abstrações que definem o modo como os indivíduos "processam" as informações recebidas do ambiente de trabalho e da própria atividade em que estão envolvidos (BENDASSOLLI e SOBOLL, 2011).

Outro uso profícuo da Ergologia nos Estudos Organizacionais sobre trabalho pode se dar no debate a respeito da noção de competência, ora entendida como um conjunto de qualificações ou características subjacentes à pessoa e que the permitem realizar determinado trabalho ou lidar com dada situação (BOYATZIS, 1982; MCCLELLAND, 1973); ora associada não a um conjunto de atributos da pessoa, mas sim às suas realizações em determinado contexto, isto é, àquilo que o indivíduo produz ou realiza no trabalho (LEBOTERF, 2003; ZARIFIAN, 2003; 2001). Para Durrive (2011), Schwartz (2010e) e Schwartz, Duc e Durrive (2010a; 2010c), é um equívoco abordar a questão da competência supondo elementos separados que comporiam um agir individual. Conforme esses autores, o corpo-si engaja-se para fazer algo graças a uma combinatória problemática de ingredientes heterogêneos que não podem ser todos avaliados nos mesmos moldes, questionando assim as "grades de competências" ou as listas de "traços de competências" a serem desenvolvidos em determinados trabalhadores dependendo da atividade que executam. Os autores relacionam competência a situações de trabalho, que são situações de vida e, portanto, listar competências necessárias para o trabalho equivaleria a listar competências necessárias para viver.

A lente ergológica pode ser utilizada, ainda, para lançar um novo olhar sobre a Qualidade de Vida no Trabalho (QVT), tradicionalmente abordada do ponto de vista de medidas a serem adotadas pelas organizações no intuito de amenizar a tríade trabalho-sofrimento-adoecimento. Cabe ampliar a discussão e direcioná-la para a necessidade de se admitir a renormalização como necessária, uma vez que ela é também expressão do desejo de saúde por parte do trabalhador. Desejo este manifesto na tentativa de realizar suas atividades considerando as próprias normas e singularidades, visto que ter saúde não é enquadrar-se no discurso da normalidade, mas sim ser normativo (CANGUILHEM, 1999).

Ainda contextualizando as potencialidades da Ergologia para os Estudos Organizacionais, algumas consequências para práticas administrativas também podem ser apontadas, de acordo com o que se expõe adiante. 


\section{Possíveis consequências para práticas administrativas}

Uma vez que o aporte teórico-conceitual da abordagem ergológica leva a repensar diversos pressupostos enraizados na lógica administrativa clássica, ele convida em especial a revisitar as práticas de Gestão de Pessoas. Nesse sentido, o principal impacto da Ergologia para as práticas administrativas consiste em evidenciar algo notório a que Schwartz (2000b) chama atenção: a necessidade de se pensar o trabalho não por meio de "grades", "modelos", "comportamentos", "lógicas sociais" e outros signos socialmente denotados e conotados, uma vez que uma dimensão de potencialidades alternativas habita o estado das coisas e deve ser vista em potência, mesmo que infinitesimal. Em outros termos, o trabalho como uso de si por si e pelos outros, como um modo de enfrentamento de situações em parte sempre inantecipáveis, é o que em grande medida garante seu desenrolar eficaz e eficiente ante as variabilidades e imprevistos que sempre vêm perturbá-lo no ato real.

Considerando isso, cabe resgatar que, por um lado, as teorias cognitivo-comportamentais - de grande impacto para as práticas administrativas - estão historicamente ligadas à previsão e ao controle do comportamento com vistas ao desempenho e ao desenvolvimento de instrumentos de controle para a gestão, apresentando-se como capazes de instrumentalizar o gerenciamento dos fatores humanos no trabalho e promover a adaptação do indivíduo aos imperativos do desempenho e da eficiência (BENDASSOLLI e SOBOLL, 2011). Por outro lado, a perspectiva ergológica busca revelar exatamente o que escapa à instrumentalização e situar aí a potencialidade responsável pela eficácia e eficiência diante da impossibilidade de antecipação completa do real.

Nessa perspectiva, coloca-se em foco a necessidade de se questionar ferramentas como as de recrutamento, seleção, avaliação, remuneração e desenvolvimento e os pressupostos com base nos quais se constrói o ato mesmo de "recrutar", "selecionar", "avaliar", "remunerar" e "desenvolver", uma vez que estes, historicamente, têm como parâmetro e se pautam em categorias pré-definidas, às quais se remete e se busca enquadrar o real. A Ergologia, por sua vez, ao focar as singularidades dos usos de si e o constante retrabalho de normas antecedentes, revela a fragilidade das ferramentas generalistas e a potência do trabalho em ato que delas escapa e que se situa na defasagem entre trabalho prescrito e trabalho real. Trata-se, sem dúvida, de um debate polêmico e incipiente, cuja continuidade exige discussões aprofundadas e cautelosas, aqui impossíveis, tendo em vista o caráter propedêutico deste artigo.

\section{Considerações Finais}

Neste artigo buscou-se apontar e demarcar como profícuo o uso da abordagem ergológica, desenvolvida pelo filósofo francês Yves Schwartz, por pesquisadores da área de estudos organizacionais. Por meio dos pontos abordados, podem-se delimitar, de modo conciso, os propósitos de uso dessa abordagem nos estudos organizacionais sobre trabalho da seguinte forma: deslocar o foco do trabalho prescrito (planejado, organizado, dirigido, controlado) para o trabalho real e considerar toda a complexidade que aí reside, relativa: à sua dimensão de uso de si por si e pelos outros; aos valores e às normas antecedentes, com base nos quais são tomadas as decisões pelos trabalhadores; à pertinência dos coletivos em detrimento dos grupos hierárquicos; aos saberes constituídos no enfrentamento das situações reais; ao trabalho como ambiente de vida, em que a reconfiguração de normas se relaciona à saúde; ao trabalho como ambiente de aprendizagem, em que saberes práticos se constituem e são em grande medida responsáveis por suprir as lacunas deixadas pelos saberes técnicos; ao trabalho como possibilidade de confronto entre saberes práticos e técnicos, numa dialética fecunda; à reformulação sempre inacabada dos conceitos e saberes científicos acumulados; e, em especial, à potencialidade que reside nas singularidades do ato real de trabalho e que escapa às ferramentas e aos modelos enquanto generalizações e prescrições.

Cogitando uma "ergogestão" ou "ergoadministração", Trinquet (2010, p. 110) aponta ser necessário reafirmar a "[...] ideia de se levar a normatização das atividades coletivas dos outros apenas até certo grau, 
pois ela induz a limites, sendo a sua rigidez impossível ou mesmo patogênica, no próprio sentido do termo". Convém, portanto, a cada gestor, a cada organizador do trabalho, levar em conta os imperativos de toda atividade humana e a contradição entre normas necessárias e renormalizações considerando as situações sempre singulares. Para isso, é preciso adaptar-se a cada situação e, nesse sentido, como bem coloca o autor mencionado (p. 110), “[...] a gestão coloca-se mais como uma arte do que como uma técnica".

Sobre tudo o que se expôs, não se trata de conjecturar ingenuamente a possibilidade de abrir mão de instrumentos e ferramentas gerenciais. Trata-se, pelo contrário, de seu retrabalho, em um uso sadio, contextualizado e reflexivo, considerando suas limitações ante a complexidade da atividade humana. Tal consideração, quando levada a sério, pode abrir portas para o desenvolvimento e aprimoramento de instrumentos mais contextualizados, adequados e renovados, uma vez que é compromisso da Ergologia conhecer de perto o trabalho e, assim, postular problemas e elucidar soluções e melhoramentos.

Nesse sentido, à concepção de gestão predominante na Administração seria incorporada a noção de renormalização via diálogo com aqueles que, nos discursos organizacionais da contemporaneidade, lhes são caros, os trabalhadores. Por meio do reconhecimento da gestão exercida em atividade, vários aspectos paradoxais da gestão (BENDASSOLLI e SOBOLL, 2011), discutidos também por Gaulejac (2005), poderiam ser antecipados e normatizados num contexto de gestão ad hocrática (MARX, 2011). Esses aspectos e inter-relações, no entanto, podem ser pensados e trabalhados em textos futuros, tendo como ponto de partida as possibilidades de pesquisas a serem exploradas no campo dos estudos organizacionais e que foram discutidas neste artigo. 


\section{Referências}

AKTOUF, O. Pós-globalização, administração e racionalidade econômica: a síndrome do avestruz. São Paulo: Atlas, 2004.

ATHAYDE, M.; BRITO, J. Ergologia e clínica do trabalho. In: BENDASSOLLI, P. F.; SOBOLL, L. A. P. (Org.). Clínicas do trabalho: novas perspectivas para compreensão do trabalho na atualidade. São Paulo: Atlas, 2011. 258-281 p.

BENDASSOLLI, P. F.; SOBOLL, L. A. P. Introdução às clínicas do trabalho: aportes teóricos, pressupostos e aplicações. In: BENDASSOLLI, P. F.; SOBOLL, L. A. P. (Org.). Clínicas do trabalho: novas perspectivas para compreensão do trabalho na atualidade. São Paulo: Atlas, 2011. 3-21 p..

BIANCO, M. F.; ALMEIDA, H. A. C. D.; BINDA, J. Análise do trabalho numa perspectiva singular de gestão: um estudo em diferentes Unidades de Saúde da Família. In: FERNANDES, S. C.; GOMES, E. B. F. (Org.). Tecnologias de gestão e subjetividades: por uma abordagem multidisciplinar. v. III. Vitória: EDUFES, 2012.

BOTECHIA, F.; ATHAYDE, M. Um regime de produção de saberes sobre o trabalhar e suas relações: a comunidade ampliada de pesquisa. In: ENCONTRO NACIONAL DA ASSOCIAÇÃO BRASILEIRA DE PSICOLOGIA SOCIAL, 14., 2007, Rio de Janeiro. Anais eletrônicos... Disponível em: < http://www.abrapso.org.br/siteprincipal/anexos/AnaisXIVENA/conteudo/pdf/trab_completo_33.pdf>. Acesso em: 1 jul. 2013.

BOYATZIS, R. E. The competent management: a model for effective performance. Nova York: John Wiley, 1982.

BRITO, J. Saúde do trabalhador: reflexões a partir da abordagem ergológica. In: FIGUEIREDO, M. et al. (Org.). Labirintos do trabalho: interrogações e olhares sobre o trabalho vivo. Rio de Janeiro: DP\&A, 2004. 91-114 p.

; ARANHA, A. V. S. A construção metodológica na pesquisa sobre atividade de trabalho a partir da abordagem ergológica. Trabalho \& Educação, Belo Horizonte, v. 20, n. 1, p. 85-101, jan./abr. 2011.

BURRELL, G.; MORGAN, G. Sociological paradigms and organizational analysis. London: Heinemann Educational Books, 1979.

CANGUilhem, G. Milieu et normes de l'homme au travail. Cahiers Internationaux de Sociologie, Paris, v. 3 , 1947.

La connaissance de la vie. Paris: Vrin, 1992.

Etudes d'histoire et de philosophie des sciences. Paris: Vrin, 1994.

Le normal e le pathologique. Paris: PUF, 1999.

CARRETEIRO, T. C. O.; BARROS, V. A. Clínicas do trabalho: contribuições da psicossociologia no Brasil. In: BENDASSOLli, P. F.; SOBOLL, L. A. P. (Org.). Clínicas do trabalho: novas perspectivas para compreensão do trabalho na atualidade. São Paulo: Atlas, 2011. 3-21 p.

CHANLAT, J. F. O individuo na organização: dimensões esquecidas. São Paulo: Atlas, 1994.

CLEGG, S. Modern organizations: organization studies in the postmodern world. Londres: Sage, 1990.

CLOT, Y. A função psicológica do trabalho. 2. ed. Petrópolis: Vozes, 2007.

Travail et pouvoir d'agir. Paris: PUF, 2008a.

2008b.

Le travail sans l'homme? Pour une psychologie des millieux de travail et de vie. Paris: La Découverte, 
. L'apport de François Tosquelles à la clinique du travail. Posfácio à $2^{\text {a }}$ edição. Le travail thérapeutique em psychiatrie. Toulouse: Érès, 2009.

et al. Les entretiens en autoconfrontation croisée: une méthode en clinique de l'activité. Éducation Permanente, n. 146, 2001.

COELHO-JUNIOR, F. A.; BORGES-ANDRADE, J. E. Percepção de cultura organizacional: uma análise empírica da produção científica brasileira. Psico-USF (Impr.), Itatiba, v. 9, n. 2, p. 191-199, dez. 2004.

DEJOURS, C. Travail: usure mentale. Paris: Centurion, 1980.

A loucura do trabalho: estudo de psicopatologia do trabalho. São Paulo: Oboré, 1987.

Le facteur humain. Paris: PUF, 1995.

Psychologie clinique du travail et tradition comprehensive. In: CLOT, Y. Les histoires de la psychologie du travail: approche pluri-disciplinaire. Paris: Octarès, 1996a.

Revue Internationale de Psychosociologie. Psychodynamique du travail, n. 5, v. 3, 1996 b.

. Travail, usure mentale (nouvelle edition augmentée). Paris: Bayard, 2000.

. et al. Psicodinâmica do trabalho: contribuições da Escola Dejouriana à análise da relação prazer, sofrimento e trabalho. São Paulo: Atlas, 1993.

DURAFFOURG, J.; DUC, M.; DURRIVE, L. O trabalho e o ponto de vista da atividade. In: SCHWARTZ, Y.; DURRIVE, L. (Org.). Trabalho \& Ergologia: conversas sobre a atividade humana. 2. ed. Niterói: EdUFF, 2010. 47-87 p.

DURRIVE, L. A atividade humana, simultaneamente intelectual e vital: esclarecimentos complementares de Pierre Pastré e Yves Schwartz. Trab. Educ. Saúde, Rio de Janeiro, v. 9, supl. 1, p. 47-67, 2011.

; JACQUES, A. M. O formador ergológico ou "Ergoformador": uma introdução à ergoformação. In: SCHWARTZ, Y.; DURRIVE, L. (Org.). Trabalho \& Ergologia: conversas sobre a atividade humana. 2. ed. Niterói: EdUFF, 2010. p. 295-307.

; SCHWARTZ, Y. Revisões temáticas: glossário da Ergologia. Laboreal, v. 4, n. 1, p. 23-28, 2008.

ENRIQUEZ, E. L’organisation en analyse. Paris: PUF, 1992.

GAULEJAC, V. La société malade de la gestion: idéologie gestionnaire, pouvoir managérial et harcèlement social. Paris: Editions du Seuil, 2005.

GORZ, A. O imaterial: conhecimento, valor e capital. São Paulo: Annablume, 2005.

GUÉRIN, F. et al. Compreender o trabalho para transformá-lo: a prática da Ergonomia. São Paulo: Edgard Blücher, 2001.

HASSARD, J. Postmodernism and organizational analysis: an overview. In: HASSARD, J.; PARKER, M. Postmodernism and organizations. Londres: Sage Publications, 1993. 1-23 p.

HENNINGTON, A. F.; CUNHA, D. M.; FISCHER, M.. C. B. Trabalho, educação, saúde e outros possíveis: diálogos na perspectiva ergológica. Trab. Educ. Saúde, Rio de Janeiro, v. 9, n. supl. 1, p. 5-18, 2011.

LE-BOTERF, G. Desenvolvendo a competência dos profissionais. 3. ed. Porto Alegre: Artmed, 2003. 
LIMA, E. L. N.; BIANCO, M. de F. Análise de situações de trabalho: gestão e os usos de si dos trabalhadores de uma empresa do ramo petrolífero. Cad. EBAPE. BR., Rio de Janeiro, v. 7, n. 4, p. 629-648, dez. 2009.

LIMA, M. E. A. Abordagens clínicas e saúde mental no trabalho. In: BENDASSOLLI, P. F.; SOBOLL, L. A. P. (Org.). Clínicas do trabalho: novas perspectivas para compreensão do trabalho na atualidade. São Paulo: Atlas, 2011. 227-257 p.

MACHADO, L. et al. Apontamentos sobre o cotidiano de alguns trabalhadores. In: JUNQUILHO, G. S. et al. (Org.). Tecnologias de gestão e subjetividades: por uma abordagem multidisciplinar. Vitória: EDUFES, 2007, v. II. 173-197 p.

MARX, R. Organização do trabalho para a inovação: uma avaliação crítica dos projetos e da implantação de trabalho em grupos com autonomia. São Paulo: Atlas, 2011.

MCCLELLAND, D. Testing for competence rather than intelligence. American Psychologist, v. 28, n. 1, p. 1-14, 1973.

MEZADRE, S. B. B.; BIANCO, M. F. Análise ergológica da gestão das atividades dos técnicos em eletrônica. In: SIMPÓSIO DE EXCELÊNCIA EM GESTÃO E TECNOLOGIA, 8., 2011, Resende. Anais eletrônicos... Disponível em: <http://www.aedb.br/seget/artigos11/50514608.pdf>. Acesso em: 1 jul. 2012.

MINTZBERG, H. El poder en la organización. Barcelona: Editorial Ariel S.A., 1992.

Criando organizações eficazes: estruturas em cinco configurações. São Paulo: Atlas, 1995.

NOUROUDINE, A. Como conhecer o trabalho quando o trabalho não é mais o trabalho? Trabalho, Educação e Saúde, Rio de Janeiro, v. 9, n. supl. 1, p. 69-83, 2011.

ODDONE, I. Experiência. Laboreal, v. 3, n. 1, p. 52-53, 2007.

PAGÈS, M. et al. L'emprise de l'organisation. Paris: PUF, 1980.

PASTRÉ, P. Apprendre à faire. In: BOURGEOIS, E.; CHAPELlE, G. (Dir.). Apprendre et faire apprendre. Paris: PUF, 2006. 109-121 p.

PETTIGREW, A. M. The politics of organizational decision making. London: Tavistock, 1973.

PFEFFER, J. Power in organizations. Marshfield: Pitman, 1981.

RABARDEL, P.; PASTRÉ, P. Modéles du sujet pour la conception: dialectiques activités developpement. Toulouse: Octarés Éditions, 2009.

SCHWARTZ, Y. Os ingredientes da competência: um exercício necessário para uma questão insolúvel. Educação \& Sociedade, Campinas, v. 19, n. 65, p. 101-140, dez. 1998.

A comunidade científica ampliada e o regime de produção de saberes. Belo Horizonte: Trabalho e Educação, n. 7, p. 38-46, jul./dez 2000a.

. Trabalho e uso de si. Pro-Posições, São Paulo, v. 1, n. 5, p. 34-50, jul. 2000 b.

Ergonomia, filosofia e exterritorialidade. In: DANIELLOU, F. (Coord.). A Ergonomia em busca dos seus princípios: debates epistemológicos. São Paulo: Edgard Blüncher, 2001.141-180 p.

. Disciplina Epistêmica, Disciplina Ergológica - paidéia e politeia. Pro-Posições, (Unicamp), v. 13, n. 1, p. 126149, jan./abr. 2002.

. Circulações, dramáticas, eficácias da atividade industriosa. Trabalho, Educação e Saúde, Rio de Janeiro, v. 2 , n. 1, p. 33-35, 2004. 
A dimensão coletiva do trabalho e as Entidades Coletivas Relativamente Pertinentes (ECRP). In: SCHWARTZ, Y.; DURRIVE, L. (Org.). Trabalho \& Ergologia: conversas sobre a atividade humana. 2. ed. Niterói: EdUFF, 2010a. 147-164 p.

. A experiência é formadora? Educação \& Realidade, Porto Alegre, v. 35, n. 1, p. 35-48, 2010 b.

. A trama e a urdidura. In: SCHWARTZ, Y.; DURRIVE, L. (Org.). Trabalho \& Ergologia: conversas sobre a atividade humana. 2. ed. Niterói: EdUFF, 2010c. 103-109 p.

Reflexão em torno de um exemplo de trabalho operário. In: SCHWARTZ, Y.; DURRIVE, L. (Org.). Trabalho \& Ergologia: conversas sobre a atividade humana. 2. ed. Niterói: EdUFF, 2010d. 37-46 p.

. Uso de si e competência. In: SCHWARTZ, Y.; DURRIVE, L. (Org.). Trabalho \& Ergologia: conversas sobre a atividade humana. 2. ed. Niterói: EdUFF, 2010e. 205-221 p.

Conceituando o trabalho, o visível e o invisível. Trab. Educ. Saúde, Rio de Janeiro, v. 9, p. 19-45, 2011.

SCHWARTZ, Y.; DI RUZZA, R.; LE BRIS, R. Trabalho, emprego e cidadania. In: SCHWARTZ, Y.; DURRIVE, L. (Org.). Trabalho \& Ergologia: conversas sobre a atividade humana. 2. ed. Niterói: EdUFF, 2010a. p. 147-164.

SCHWARTZ, Y.; DUC, M.; DURRIVE, L. A linguagem em trabalho. In: SCHWARTZ, Y.; DURRIVE, L. (Org.). Trabalho \& Ergologia: conversas sobre a atividade humana. 2. ed. Niterói: EdUFF, 2010a. 131-148 p.

O homem, o mercado e a cidade. In: SCHWARTZ, Y.; DURRIVE, L. (Org.). Trabalho \& Ergologia: conversas sobre a atividade humana. 2. ed. Niterói: EdUFF, 2010b. 247-273 p.

Técnicas e competências. In: SCHWARTZ, Y.; DURRIVE, L. (Org.). Trabalho \& Ergologia: conversas sobre a atividade humana. 2. ed. Niterói: EdUFF, 2010c. 85-102 p.

. Trabalho e Ergologia. In: SCHWARTZ, Y.; DURRIVE, L. (Org.). Trabalho \& Ergologia: conversas sobre a atividade humana. 2. ed. Niterói: EdUFF, 2010d. 25-36 p.

Trabalho e uso de si. In: SCHWARTZ, Y.; DURRIVE, L. (Org.). Trabalho \& Ergologia: conversas sobre a atividade humana. 2. ed. Niterói: EdUFF, 2010e. 189-204 p.

SOUZA, E. M.; BIANCO, M. F. A Ergologia - uma alternativa analítica para os Estudos do Trabalho. In: CONGRESSO LATINOAMERICANO DE SOCIOLOGÍA DEL TRABAJO, 5., 2007, Montevideo. Anais... Montevideo: ALAST, 2007.

TELLES, A. L.; ALVAREZ, D. Interfaces ergonomia-ergologia: uma discussão sobre trabalho prescrito e normas antecedentes. In: FIGUEIREDO, M. et al. (Org.). Labirintos do trabalho: interrogações e olhares sobre o trabalho vivo. Rio de Janeiro: DP\&A, 2004. 63-90 p.

TRINQUET, P. Trabalho e Educação: o método ergológico. Revista HISTEDBR, Campinas, v. 10, n. número especial, p. 93-113, ago. 2010.

VIEIRA-JÚNIOR, P. R.; SANTOS, E. H. A gênese da perspectiva ergológica: cenário de construção e conceitos derivados. Trabalho \& Educação, Belo Horizonte, v. 21, n. 1, p. 83-100, jan./abr.2012.

WATSON, T. J. Group ideologies and organizational change. Journal of management studies, v. 19, n. 3, p. 259-275, 1982.

ZARIFIAN, P. Objetivo competência: por uma nova lógica. São Paulo: Atlas, 2001.

O modelo da competência: trajetória histórica, desafios atuais e propostas. São Paulo: Ed. SENAC BN, 2003. 